\title{
Radical Nephrectomy Performed by Open, Laparoscopy with or without Hand-Assistance or Robotic Methods by the Same Surgeon Produces Comparable Perioperative Results
}

\author{
Tanya Nazemi, Anton Galich, Samuel Sterrett, Douglas Klingler, Lynette Smith, K.C. Balaji \\ Division of Urological Surgery, Department of Surgery, University of Nebraska Medical Center, \\ Omaha, Nebraska, USA
}

\begin{abstract}
Purpose: Radical nephrectomy can be performed using open or laparoscopic (with or without hand assistance) methods, and most recently using the da Vinci Surgical Robotic System. We evaluated the perioperative outcomes using a contemporary cohort of patients undergoing radical nephrectomy by one of the above 4 methods performed by the same surgeon. Materials and Methods: The relevant clinical information on 57 consecutive patients undergoing radical nephrectomy from September 2000 until July 2004 by a single surgeon was entered in a Microsoft Access Database ${ }^{\mathrm{TM}}$ and queried. Following appropriate statistical analysis, $\mathrm{p}$ values $<0.05$ were considered significant.

Results: Of 57 patients, the open, robotic, laparoscopy with or without hand assistance radical nephrectomy were performed in 18,6,21, and 12 patients, respectively. The age, sex, body mass index (BMI), incidence of malignancy, specimen and tumor size, tumor stage, Fuhrman grade, hospital stay, change in postoperative creatinine, drop in hemoglobin, and perioperative complications were not significantly different between the methods. While the estimated median blood loss, postoperative narcotic use for pain control, and hospital stay were significantly higher in the open surgery method (p < $0.05)$, the median operative time was significantly shorter compared to the robotic method $(\mathrm{p}=0.02)$. Operating room costs were significantly higher in the robotic and laparoscopic groups; however, there was no significant difference in total hospital costs between the 4 groups.

Conclusions: The study demonstrates that radical nephrectomy can be safely performed either by open, robotic, or laparoscopic with or without hand assistance methods without significant difference in perioperative complication rates. A larger cohort and longer follow up are needed to validate our findings and establish oncological outcomes.
\end{abstract}

Key words: kidney neoplasms; nephrectomy; laparoscopy; robotic; surgical procedures, operative

Int Braz J Urol. 2006; 32: 15-22

\section{INTRODUCTION}

Nephrectomy for the treatment of renal disease was first performed in the 1860s (1). Since Robson's first description of radical nephrectomy (RN) for renal tumors in the year 1963, RN has been traditionally performed by open methods through rela- tively large abdominal or flank incisions (2). Within the last decade, RN is more frequently being performed using laparoscopy with or without hand assistance, and most recently using the da Vinci Surgical Robotic System $(3,4)$. Studies have established the comparability in perioperative and oncological outcomes between laparoscopy and open RN meth- 
ods $(5,6)$. Most of these studies include patients undergoing RN by either open or laparoscopic methods by different surgeons and therefore, were unable to evaluate the impact on the individual surgeon's performance on the outcome independent of the method used in performing the procedure (5). Several studies evaluating outcomes of patients undergoing radical surgery for prostate and bladder cancer by open methods have demonstrated that the performing surgeon is an independent predictor of outcome $(7,8)$. Therefore, in this study we analyzed the perioperative outcome using a contemporary cohort of patients undergoing RN by different methods (open, laparoscopy with hand assistance (HAL), laparoscopy without hand assistance, robotic) performed by the same surgeon, thereby minimizing the impact of different surgeons performing the procedure on perioperative outcome.

\section{MATERIALS AND METHODS}

The relevant clinical information on 57 consecutive patients undergoing radical nephrectomy from September 2000 through July 2004 by a single surgeon was entered in a Microsoft Access Database $^{\text {TM }}$ and queried. Prior to initiation of Laparoscopic and Robotic Surgery Program (LRSP) at our institution in January of 2001, all patients underwent radical nephrectomy by conventional open method. However, since the inception of LRSP all the radical nephrectomies were performed using minimally invasive techniques, including pure laparoscopy, hand assisted laparoscopy, and robot assisted surgery. Open radical nephrectomies continued to be performed in our institution on the patients with medical contraindications to laparoscopy. Hand assisted laparoscopy was a method of choice for radical nephrectomies in the early part of our series because it facilitates transfer of open surgical skills to laparoscopic surgery. However, with increasing experience, pure laparoscopic method was more frequently used to complete radical nephrectomy and hand assistance was limited to complex cases including large masses, extensive intra-abdominal adhesions, uncontrollable bleeding or failure to progress. The robotic method was used to es- tablish feasibility of using the robot to perform radical nephrectomy as previously published (4). An Institutional Review Board (IRB) exempt status for the study was obtained because all patient identifiers were deleted after obtaining pertinent clinical information and subjects were never identified. The information analyzed included age, sex, body mass index (BMI), operative time, postoperative narcotic use including need to use patient controlled analgesia (PCA) or total quantity of morphine equivalent used, estimated blood loss, hospital stay, change in postoperative creatinine and hemoglobin, presence or absence of malignancy, final pathology of intact specimens including specimen size, tumor size, stage, Fuhrman grade, and perioperative complications.

Postoperatively, several patients received morphine sulfate for analgesia by PCA pump. In this study, we used the need to use PCA for postoperative analgesia as an indicator of increased postoperative pain. Because the total amount of morphine used through the PCA was variable, we were unable to precisely quantify the milligrams of morphine used. However, when the patients' pain improved, they either were switched to oral pain medications or were given measured amount of morphine intravenously as needed. Therefore, for the purpose of analysis, we categorized the patients based on PCA use for postoperative pain control when accurate measurements of morphine use were not obtainable.

Finally, a cost analysis was performed comparing the operating room charges and total hospital costs for a randomly selected group of patients from each group.

\section{Statistical Analysis}

Continuous variables were compared using the Wilcoxon rank sum test due to the skewed nature of the variables and categorical variables were compared using Fisher's exact test. P-values were compared to a significance level of 0.05 . Pairwise comparisons using the non-parametric Wilcoxon rank sum test were carried out to compare perioperative outcomes between the 4 methods. The alpha level was adjusted to account for the multiple comparisons using the Bonferroni method (9). 
Table 1 - Comparison of characteristics of patients undergoing radical nephrectomy by different methods.

\begin{tabular}{|c|c|c|c|c|c|c|}
\hline Characteristics & & $\begin{array}{c}\text { Open } \\
\text { Method } \\
(n=18)\end{array}$ & $\begin{array}{l}\text { Robotic } \\
\text { Method } \\
(\mathrm{n}=6)\end{array}$ & $\begin{array}{c}\text { Hand Assisted } \\
\text { Laparoscopic Method } \\
(\mathrm{n}=21)\end{array}$ & $\begin{array}{l}\text { Laparoscopic } \\
\text { Method } \\
(\mathrm{n}=12)\end{array}$ & p Value \\
\hline Age (years) & $\begin{array}{c}\text { Median } \\
\text { Range }\end{array}$ & $\begin{array}{c}57 \\
38-98\end{array}$ & $\begin{array}{c}67.5 \\
44-78\end{array}$ & $\begin{array}{c}62 \\
27-81\end{array}$ & $\begin{array}{c}69 \\
43-76\end{array}$ & 0.59 \\
\hline Sex & $\begin{array}{l}\text { Male } \\
\text { Female }\end{array}$ & $\begin{array}{c}15(83 \%) \\
3(17 \%)\end{array}$ & $\begin{array}{l}5(83 \%) \\
1(17 \%)\end{array}$ & $\begin{array}{c}15(71 \%) \\
6(29 \%)\end{array}$ & $\begin{array}{l}9(75 \%) \\
3(25 \%)\end{array}$ & 0.83 \\
\hline BMI & $\begin{array}{l}\text { Median } \\
\text { Range }\end{array}$ & $\begin{array}{c}28.2 \\
15.9-50.3\end{array}$ & $\begin{array}{c}27.6 \\
20.9-32.9\end{array}$ & $\begin{array}{c}29.2 \\
22.3-46.9\end{array}$ & $\begin{array}{c}27.5 \\
19.2-39.8\end{array}$ & 0.83 \\
\hline $\begin{array}{l}\text { Final pathological } \\
\text { diagnosis }\end{array}$ & $\begin{array}{c}\text { Malignant } \\
\text { Oncocytoma } \\
\text { Benign }\end{array}$ & $\begin{array}{c}14(78 \%) \\
0 \\
4(22 \%)\end{array}$ & $\begin{array}{c}5(83 \%) \\
0 \\
1(17 \%)\end{array}$ & $\begin{array}{c}15(71 \%) \\
1(5 \%) \\
5(24 \%)\end{array}$ & $\begin{array}{l}8(67 \%) \\
2(17 \%) \\
2(17 \%)\end{array}$ & 0.76 \\
\hline $\begin{array}{l}\text { Specimen size - } \\
\text { Longest dimension } \\
(\mathrm{cm})\end{array}$ & $\begin{array}{c}\text { Median } \\
\text { Range }\end{array}$ & $\begin{array}{c}15 \\
8-25\end{array}$ & $\begin{array}{c}12 \\
10-18\end{array}$ & $\begin{array}{c}15 \\
8-25\end{array}$ & $\begin{array}{l}14.5 \\
7-23\end{array}$ & 0.66 \\
\hline $\begin{array}{l}\text { Tumor size - } \\
\text { Longest dimension } \\
(\mathrm{cm})\end{array}$ & $\begin{array}{c}\text { Median } \\
\text { Range }\end{array}$ & $\begin{array}{l}5.5 \\
1.8-15\end{array}$ & $\begin{array}{c}4.5 \\
2.8-5.5\end{array}$ & $\begin{array}{c}4.25 \\
1.5-15 \\
15(71 \%)\end{array}$ & $\begin{array}{c}3.95 \\
2.3-15.0\end{array}$ & 0.94 \\
\hline $\begin{array}{l}\text { Incidence of } \\
\text { malignancy }\end{array}$ & $\begin{array}{l}\text { Renal cell } \\
\text { cancer }\end{array}$ & $14(78 \%)$ & $5(83 \%)$ & & $8(67 \%)$ & 0.87 \\
\hline $\begin{array}{l}\text { Stage (TNM } \\
\text { staging, } 1997 \\
\text { AJCC) }(17)\end{array}$ & $\begin{array}{c}\text { T1a } \\
\text { T1b } \\
\text { T2 } \\
\text { T3a } \\
\text { T3b } \\
\text { T4 } \\
\text { T3a M1 }\end{array}$ & $\begin{array}{c}3(21 \%) \\
4(29 \%) \\
3(21 \%) \\
3(21 \%) \\
- \\
- \\
1(7 \%)\end{array}$ & $\begin{array}{c}2(40 \%) \\
2(40 \%) \\
- \\
- \\
- \\
- \\
1(20 \%)\end{array}$ & $\begin{array}{c}7(47 \%) \\
3(20 \%) \\
3(20 \%) \\
2(13 \%) \\
- \\
- \\
-\end{array}$ & $\begin{array}{c}3(38 \%) \\
1(12 \%) \\
1(12 \%) \\
1(12 \%) \\
1(12 \%) \\
1(12 \%) \\
-\end{array}$ & 0.70 \\
\hline Fuhrman Grade & $\begin{array}{c}1 \\
2 \\
3 / 4\end{array}$ & $\begin{array}{l}1(9 \%) \\
7(64 \%) \\
3(27 \%)\end{array}$ & $\begin{array}{c}0 \\
3(60 \%) \\
2(40 \%)\end{array}$ & $\begin{array}{l}3(25 \%) \\
7(58 \%) \\
2(17 \%)\end{array}$ & $\begin{array}{c}0 \\
7(87 \%) \\
1(13 \%)\end{array}$ & 0.63 \\
\hline $\begin{array}{l}\text { Follow-up } \\
\text { (months) }\end{array}$ & $\begin{array}{c}\text { Median } \\
\text { Range }\end{array}$ & $\begin{array}{c}15 \\
1-31\end{array}$ & $\begin{array}{c}4 \\
1-10\end{array}$ & $\begin{array}{c}5 \\
1-25\end{array}$ & $\begin{array}{c}7 \\
1-21\end{array}$ & 0.07 \\
\hline Disease recurrence & & $2(20 \%)$ & 0 & 0 & 0 & 0.24 \\
\hline
\end{tabular}

BMI = body mass index. 
Table 2 - Perioperative outcomes in patients undergoing radical nephrectomy by different methods. Statistically significant pairwise comparisons ( $p<0.01$ to adjust for multiple comparisons).

\begin{tabular}{|c|c|c|c|c|c|c|}
\hline & & $\begin{array}{l}\text { Open } \\
\text { Method } \\
(n=18)\end{array}$ & $\begin{array}{l}\text { Robotic } \\
\text { Method } \\
(n=6)\end{array}$ & $\begin{array}{c}\text { Hand Assisted } \\
\text { Laparoscopic Method } \\
(\mathrm{n}=21)\end{array}$ & $\begin{array}{l}\text { Laparoscopic } \\
\text { Method } \\
(\mathrm{n}=12)\end{array}$ & p Value \\
\hline $\begin{array}{l}\text { Operative time } \\
\text { (minutes) }\end{array}$ & $\begin{array}{l}\text { Median } \\
\text { Range }\end{array}$ & $\begin{array}{c}202 \\
116-382\end{array}$ & $\begin{array}{c}345 \\
246-548\end{array}$ & $\begin{array}{c}265 \\
129-402\end{array}$ & $\begin{array}{c}237.5 \\
181-434\end{array}$ & 0.02 \\
\hline $\begin{array}{l}\text { Estimated blood } \\
\text { loss }(\mathrm{mL})\end{array}$ & $\begin{array}{l}\text { Median } \\
\text { Range }\end{array}$ & $\begin{array}{c}500 \\
75-3000\end{array}$ & $\begin{array}{c}125 \\
25-1500\end{array}$ & $\begin{array}{c}100 \\
10-1000\end{array}$ & $\begin{array}{c}125 \\
50-300\end{array}$ & 0.01 \\
\hline $\begin{array}{l}\text { Postoperative } \\
\text { change in creati- } \\
\text { nine }(\mathrm{mg} / \mathrm{dL})\end{array}$ & $\begin{array}{l}\text { Median } \\
\text { Range }\end{array}$ & $\begin{array}{c}0.15 \\
-1.0-2.9\end{array}$ & $\begin{array}{c}0.3 \\
-0.4-0.8\end{array}$ & $\begin{array}{c}0.4 \\
0-3.8\end{array}$ & $\begin{array}{c}0.4 \\
0.1-0.8\end{array}$ & 0.11 \\
\hline $\begin{array}{l}\text { Postoperative } \\
\text { drop in } \mathrm{Hgb} \\
(\mathrm{g} / \mathrm{dL})\end{array}$ & $\begin{array}{l}\text { Median } \\
\text { Range }\end{array}$ & $\begin{array}{c}-2.1 \\
-7.4-0.5\end{array}$ & $\begin{array}{c}-1.4 \\
-3.5-0.1\end{array}$ & $\begin{array}{c}-1.7 \\
-4.2-1.1\end{array}$ & $\begin{array}{c}-2.3 \\
-3.5-0.6\end{array}$ & 0.30 \\
\hline Blood transfusion & & $3(16 \%)$ & $1(16 \%)$ & $5(24 \%)$ & $2(17 \%)$ & 0.9 \\
\hline $\begin{array}{l}\text { Postoperative } \\
\text { analgesia }\end{array}$ & $\begin{array}{l}\text { PCA pump } \\
\text { Other }\end{array}$ & $\begin{array}{l}6(75 \%) \\
2(25 \%)\end{array}$ & $\begin{array}{c}0 \\
6(100 \%)\end{array}$ & $\begin{array}{c}3(14 \%) \\
18(86 \%)\end{array}$ & $\begin{array}{c}2(17 \%) \\
10(83 \%)\end{array}$ & 0.0035 \\
\hline $\begin{array}{l}\text { Postoperative } \\
\text { morphine } \\
\text { equivalent use for } \\
\text { analgesia (mg) }\end{array}$ & $\begin{array}{l}\text { Median } \\
\text { Range }\end{array}$ & $\begin{array}{c}5.5 \\
1-10\end{array}$ & $\begin{array}{c}19.0 \\
2-212\end{array}$ & $\begin{array}{c}16 \\
0-210\end{array}$ & $\begin{array}{c}30 \\
0-58\end{array}$ & 0.37 \\
\hline $\begin{array}{l}\text { Hospital stay } \\
\text { (Days) }\end{array}$ & $\begin{array}{c}\text { Median } \\
\text { Range }\end{array}$ & $\begin{array}{c}5 \\
3-11\end{array}$ & $\begin{array}{c}3 \\
2-5\end{array}$ & $\begin{array}{c}4 \\
1-61\end{array}$ & $\begin{array}{c}4 \\
3-12\end{array}$ & 0.03 \\
\hline $\begin{array}{l}\text { Perioperative } \\
\text { complication rate }\end{array}$ & $\mathrm{N}(\%)$ & $3(17 \%)$ & $1(18 \%)$ & $4(19 \%)$ & $2(17 \%)$ & 1.00 \\
\hline
\end{tabular}

Operative time $=$ robotic method vs. open method; Estimated blood loss = open method vs. hand assisted laparoscopic method and open method vs. laparoscopic method; Postoperative analgesia = open method vs. hand assisted laparoscopic method and open method vs. robotic method; Hospital stay = open method vs. robotic method.

\section{RESULTS}

Of 57 patients, the open, robotic, laparoscopy with or without hand assistance $\mathrm{RN}$ were performed in $18,6,21$, and 12 patients, respectively. The patient characteristics are listed in Table-1, which were not significantly different between the four methods. The perioperative outcomes are tabulated in Table-2. There were no positive surgical margins in any of patients with malignancy. The postoperative change in creatinine, drop in hemoglobin, and perioperative complication rates were similar between the 4 methods. The 
operative time was significantly longer in the robotic method 345 (246-548) minutes compared to the open method, $202(116-382)$ minutes $(p=0.02)$. There were no statistical differences in operating time between open, HAL, and laparoscopic methods. However, the median estimated blood loss was significantly higher in the open method 500 (75-3000) mL compared HAL, and laparoscopic methods; 100 (10-1000) and 125 (50-300) $\mathrm{mL}$ respectively $(\mathrm{p}=0.01)$. The patients who underwent open nephrectomy tended to have higher rates of postoperative patient controlled analgesia (PCA) use compared to robotic and HAL methods at $75 \%$ versus $0 \%$ and $14 \%$, for the robotic and HAL methods respectively $(\mathrm{p}=0.0035)$. The median hospital stay for patients undergoing RN by robotic methods was significantly shorter compared to open method, 3 vs. 5 days ( $\mathrm{p}<0.01)$. A total of $10(17 \%)$ perioperative complications and $2(3.8 \%)$ deaths occurred in the entire study cohort. One patient died on postoperative day 10 from aspiration following open radical nephrectomy, and the other death occurred in a patient on postoperative day 6 secondary to fulminant pancreatitis following laparoscopic left radical nephrectomy. The perioperative complication rates between the four methods were not significantly different; $17 \%, 18 \%, 19 \%$, and $17 \%$ for open, robotic, HAL, and laparoscopic methods respectively ( $\mathrm{p}=$ 1.00). The morbidities following $\mathrm{RN}$ by method of surgery are detailed in Table-3. Of the 57 patients, 11 open $(61 \%), 6$ robotic $(100 \%), 12$ hand assisted $(57 \%)$, and 4 pure laparoscopic $(33 \%)$ cases were available for cost analysis. Mean operating room costs were US\$ 4,533, US\$ 10,252, US\$ 8,432, and US\$ 7,781 , for open, robotic, hand assisted, and laparoscopic cases, respectively $(\mathrm{p}=0.007)$. Total mean hospital costs were US\$ 25,503, US\$ 35,756, US\$ 30,417, and US\$ 30,293 for open, robotic, hand assisted, and pure laparoscopic cases, respectively ( $\mathrm{p}$ $=0.36)$.

\section{COMMENTS}

Most recently, the da Vinci Surgical Robotic System has been added to the armamentarium of minimally invasive surgery and is being increasingly used to perform complex urologic procedures $(10,11)$. We have previously published on the feasibility of robotic radical nephrectomy, and in this study, we evaluated the perioperative outcomes of patients undergoing $\mathrm{RN}$ by one of the four contemporary methods; open, robotic, laparoscopic methods with or without hand assistance (4). The current study includes patients who have undergone RN by one of the four methods performed by a single surgeon, thereby minimizing the impact on perioperative outcome of different surgeons performing the procedure.

Our study demonstrates that RN can be performed by any one of the four methods with comparable perioperative outcomes by a surgeon familiar with the techniques. While the characteristics of patients undergoing RN by four methods were not statistically different, the estimated median blood loss

Table 3 - Morbidities following radical nephrectomy by method of surgery.

\begin{tabular}{|c|c|c|c|}
\hline $\begin{array}{l}\text { Open Method } \\
(\mathrm{n}=18) \\
\text { Morbidities } \\
(\mathrm{n}=3,17 \%)\end{array}$ & $\begin{array}{c}\text { Robotic Method } \\
(\mathrm{n}=6) \\
\text { Morbidity } \\
(\mathrm{n}=1,18 \%)\end{array}$ & 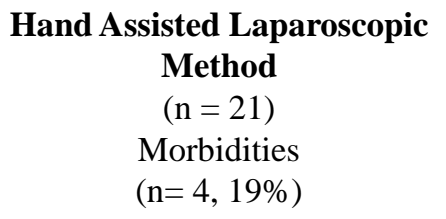 & $\begin{array}{c}\text { Laparoscopic Method } \\
(\mathrm{n}=12) \\
\text { Morbidities } \\
(\mathrm{n}=2,17 \%)\end{array}$ \\
\hline $\begin{array}{l}\text { 1. Clostridium Difficile } \\
\text { colitis } \\
\text { 2. Pneumonia } \\
\text { 3. Pneumothorax }\end{array}$ & $\begin{array}{l}\text { Stapler failure resulting } \\
\text { in renal vein bleeding } \\
\text { and conversion to } \\
\text { hand assisted } \\
\text { laparoscopic method }\end{array}$ & $\begin{array}{l}\text { 1. Perforated duodenum } \\
\text { 2. Brachial plexus injury } \\
\text { 3. Enterocutaneous } \\
\text { fistula } \\
\text { 4. Pneumonia }\end{array}$ & $\begin{array}{l}\text { 1. Wound dehiscence } \\
\text { 2. Myocardial infarction }\end{array}$ \\
\hline
\end{tabular}


of $500 \mathrm{~mL}$ (75-3000) and morphine use (need for PCA) was significantly higher in the open surgery method, and the median operative time was significantly shorter at 202 minutes (116-382) compared to one or more of the other methods $(\mathrm{p}<0.05)$. The prolonged operative time in patients undergoing $\mathrm{RN}$ by robotic method is probably related to the learning curve, as studies in literature confirm improved operative time with increasing experience with other robotic urological procedures (12). Another major limitation of RN by robotic method is increased cost. Although a detailed cost analysis is beyond the scope of this article, we demonstrated an increased mean operating room cost in the robotic and laparoscopic groups compared to the open group. Overall hospital costs, however, were not statistically different between groups. Patients treated with robotic methods had the least median length of stay in the hospital, and blood loss was significantly less than the open method and comparable to other laparoscopic methods. Although we have postulated in a prior publication that the three dimensional visualization and endowrist movements of the DSRS may facilitate performance of renal cancer surgery with IVC invasion or partial nephrectomy, it remains to be proved whether these technical advantages will result in improved clinical outcomes compared with pure laparoscopic management of cases by experienced laparoscopic urologic surgeons (4).

The perioperative complication rate for our entire cohort was $17 \%$, which is comparable to published data in the literature (13). There were no significant differences in complication rates between the four methods. However, the nature of the complications was distinctly different and dependent on the method used to perform RN. Bowel perforation occurred more frequently in patients undergoing HAL nephrectomy, whereas a solitary case of pneumothorax occurred in a patient undergoing $\mathrm{RN}$ by open method. Although we attempted to perform most open RN through an extraperitoneal approach, almost all cases of laparoscopic RN with and without hand assistance was performed using an elective transperitoneal approach. The higher incidence of bowel related complications in the HAL method was perhaps related to the transperitoneal approach and more frequent use of HAL method in patients with increased intra-abdominal adhesions. All 3 cases of bowel complications occurred in first three patients undergoing surgery by HAL. While other large nephrectomy series have also reported similar bowel injuries, both bowel injuries reported in this series occurred early in our experience, highlighting the complexity and learning curve associated with performing RN by minimally invasive techniques (13).

Several large series published in the literature comparing safety and efficacy of laparoscopic and open RN are either single or multinstitutional series where procedures were performed by multiple surgeons over an extended period of time $(14,15)$. Because the surgeon performing the procedure could be a significant factor influencing both perioperative and long term outcomes, it is unclear from the published data the exact impact of the performing surgeon on the outcome. Moreover, there are no published series in the literature on the same surgeon performing $\mathrm{RN}$ using different methods. In our study, by evaluating the perioperative outcome of patients undergoing RN by one of four contemporary methods performed by a single surgeon, we have established that a single surgeon familiar with various techniques can perform RN by any of the methods effectively with comparable complication rates, which is similar to other published nephrectomy series (13).

Although a single surgeon performed the surgeries on the entire cohort of patients included in this study, the procedures were done at a teaching institution with urology residency training program. With increasing experience, urology residents performed a greater proportion of the surgery, which demonstrates that all four methods of performing $\mathrm{RN}$ can be incorporated in to a residency-training program. Others have suggested utilizing a dedicated team of surgical assistant and ancillary staff, especially in robotic cases, to improve speed and efficacy of performing minimally invasive complex urological procedures (16). Cases in this study were performed using rotating urology residents and available but well trained ancillary staff, which suggest that our data is more likely to be reproducible in other community medical centers that may not necessarily have the resources 
of centers of excellence. We performed an average of $15 \mathrm{RN}$ each year during the study period, which confirms that $\mathrm{RN}$ by different methods inclusive of the learning curve may be performed without increased complications within a limited volume of cases by surgeons familiar with the techniques.

The primary goal of our study was to evaluate perioperative outcomes, and the data is not currently mature enough to evaluate oncological outcomes. However, patients with open $\mathrm{RN}$ have longer median follow up of 15 (1-31) months, of which $2 /$ $10(20 \%)$ developed disease recurrence with distant metastasis. Clearly, longer follow-up is needed in patients undergoing $\mathrm{RN}$ by the other three methods to compare oncological outcomes. Because the incidence of malignancy, stage and grade of malignant tumors of were similar in patients undergoing $\mathrm{RN}$ by the 4 methods, and no positive margins were noted in any of the patients, we anticipate that the oncological outcomes will also be comparable between the four methods.

Our study is limited by a relatively small sample size, which is inadequately powered to detect small differences between the four methods. The study was conducted at a single institution and our results remain to be validated by other centers where the same surgeons perform RN by different methods. We are unable to evaluate the differences in long-term oncological efficacy between the methods because of the short follow-up. Nevertheless, the study establishes that radical nephrectomy can be performed either by open, robotic, or laparoscopic with or without hand assistance methods by a single surgeon familiar with the techniques without significant difference in perioperative complication rates.

\section{CONCLUSIONS}

Our data confirms that radical nephrectomy can be performed using either open, robotic, or laparoscopy with or without hand assistance by a single surgeon without significant difference in perioperative complication rates. A larger cohort and a longer follow up are needed to validate our findings and establish oncological outcomes.

\section{CONFLICT OF INTEREST}

\author{
None declared.
}

\section{REFERENCES}

1. Jantsch M: First succesul nephrectomy performed by Gustav Simon 1869. Wien Med Wochenschr. 1969; 119: 663-4.

2. Robson CJ: Radical nephrectomy for renal cell carcinoma. J Urol. 1963; 89: 37-42.

3. Guillonneau B, Jayet C, Tewari A, Vallancien G: Robot assisted laparoscopic nephrectomy. J Urol. 2001; 166: 200-1.

4. Klingler DW, Hemstreet GP, Balaji KC: Feasibility of robotic radical nephrectomy - initial results of singleinstitution pilot study. Urology. 2005; 65: 1086-9.

5. Baldwin DD, Dunbar JA, Parekh DJ, Wells N, Shuford MD, Cookson MS, et al.: Single-center comparison of purely laparoscopic, hand-assisted laparoscopic, and open radical nephrectomy in patients at high anesthetic risk. J Endourol. 2003; 17: 161-7.

6. Wille AH, Roigas J, Deger S, Tullmann M, Turk I, Loening SA: Laparoscopic radical nephrectomy: techniques, results and oncological outcome in 125 consecutive cases. Eur Urol. 2004; 45: 483-8; discussion 488-9.

7. Eastham JA, Kattan MW, Riedel E, Begg CB, Wheeler TM, Gerigk C, et al.: Variations among individual surgeons in the rate of positive surgical margins in radical prostatectomy specimens. J Urol. 2003; 170: 22925.

8. Herr H, Lee C, Chang S, Lerner S; Bladder Cancer Collaborative Group: Standardization of radical cystectomy and pelvic lymph node dissection for bladder cancer: a collaborative group report. J Urol. 2004; 171: 1823-8; discussion 1827-8.

9. Everitt B: Statistical Methods in Medical Investigations. 2nd ed. London, E. Arnold, 1994.

10. Balaji KC, Yohannes P, McBride CL, Oleynikov D, Hemstreet GP 3rd: Feasibility of robot-assisted totally intracorporeal laparoscopic ileal conduit urinary diversion: initial results of a single institutional pilot study. Urology. 2004; 63: 51-5.

11. Hemal AK, Menon M: Robotics in urology. Curr Opin Urol. 2004; 14: 89-93.

12. Menon M, Tewari A, Peabody JO, Shrivastava A, Kaul S, Bhandari A, et al.: Vattikuti Institute prostatectomy, 


\section{Minimally Invasive Compared to Open Radical Nephrectomy}

a technique of robotic radical prostatectomy for management of localized carcinoma of the prostate: experience of over 1100 cases. Urol Clin North Am. 2004; 31: 701-17.

13. Shuford MD, McDougall EM, Chang SS, LaFleur BJ, Smith JA Jr, Cookson MS: Complications of contemporary radical nephrectomy: comparison of open vs. laparoscopic approach. Urol Oncol. 2004; 22: 121-6.

14. Makhoul B, De La Taille A, Vordos D, Salomon L, Sebe P, Audet JF, et al.: Laparoscopic radical nephrectomy for T1 renal cancer: the gold standard? A com- parison of laparoscopic vs open nephrectomy. BJU Int. 2004; 93: 67-70.

15. Lee SE, Ku JH, Kwak C, Kim HH, Paick SH: Hand assisted laparoscopic radical nephrectomy: comparison with open radical nephrectomy. J Urol. 2003; 170: 756-9.

16. Menon M, Shrivastava A, Tewari A, Sarle R, Hemal A, Peabody JO, et al.: Laparoscopic and robot assisted radical prostatectomy: establishment of a structured program and preliminary analysis of outcomes. J Urol. 2002; 168: 945-9.

\section{Correspondence address:}

Dr. K.C. Balaji

Director of Urological Oncology Research

982360, Univ of Nebraska Med Ctr

Omaha, Nebraska, 68198-2360, USA

Fax: + 1402 559-6529

E-mail:kcbalaji@unmc.edu 